\title{
Innovations in Monitoring Conveyor Belts with Implemented RFID Technology
}

\author{
Daniela Marasova ${ }^{1, *}$, Michal Cehlar ${ }^{1}$, Lubomir Ambrisko ${ }^{1}$, Vladimir Taraba ${ }^{1}$, and Nikola \\ Staricna ${ }^{1}$ \\ ${ }^{1}$ Technical University of Kosice, Faculty of Mining, Ecology, Process Control and Geotechnologies, \\ Letna 9, 04200 Kosice, Slovak Republic
}

\begin{abstract}
Belt conveyors are used as efficient conveyance systems for the continuous transportation of materials. However, they are also used for a wide range of applications in the transport of ores and non-metallic materials. The Radio Frequency Identification (RFID) system represents a key technology in many industries due to its ability of automatic data processing. The purpose of the present article is to discuss the implementation of RFID tags into fabric conveyor belts as carriers of the information on conveyor belts (ozone-induced ageing or accelerated thermal ageing, damage to cover layers and the carcass, and ignition). During the monitoring, it is important to record conveyor belt failures and damage causes, as well as other problems arising during the use of belt conveyors. The article presents the results of the experimental research on RFID tags and the analysis of their behaviour in accelerated thermal ageing. This facilitates simulating the conditions of hot vulcanisation of conveyor belts, especially when splicing (as well as producing) them, and of ozone-induced ageing of conveyor belts. The output of the article is the verification of the possibility to implement the RFID technology in the transport of mineral materials by belt conveyance systems in real operations.
\end{abstract}

\section{Introduction}

The Radio Frequency Identification, known as RFID, is a contactless identification technology which is an inseparable part of our lives, increasing productivity and comfort. This term was created for short-range (radio) devices used mainly for the transmission of digital information between a stationary site and a moving object, or between several moving objects. Is it automatic identification in which digital data, encrypted in an RFID tag or a "Smart Label", are captured by a reader that uses radio waves. Simply said, RFID is similar to the barcode technology, but it uses radio waves to capture data from the tags instead of optical scanning of barcodes on the label. RFID does not require a visible tag or label to read the stored data, this is one of the key characteristics of the RFID system [1].

\footnotetext{
*Corresponding author: daniela.marasova@tuke.sk
} 
Data are stored in a digital form in the so-called RFID tags (chips, labels) from which they may later be simply read and rewritten using radio waves. An RFID tag is a carrier of information which may have a form of a label or an enclosed form of various shapes, sizes and materials. Reading and writing data in RFID tags is carried out using an RFID reader which may have different forms (mobile terminals, stationary gates, handheld readers, etc.) The control system that facilitates mass processing of readable marks within the reader's reach and the data transmission to a related information or control system is referred to as the middleware [2].

A basic RFID system consists of RFID tags with microchips and an antenna and a reader with an antenna. An RFID tag is a small device that can be attached to an item, case, container, or pallet so that it can be identified and tracked. It is also called a transponder. The tag is composed of a microchip and an antenna. These elements are attached to a material called a substrate in order to create an inlay. Tags are categorized into three types based on the power source for communication and other functionality: active, passive, semi-passive, semi-active. The article [3] deals with the investigation of laboratory tests using active and passive UHF tags, i.e., parallel coexistence of the active and passive RFID technologies within automatic data identification and collection.

A reader transmits electromagnetic waves to which the tag's antenna is preset. The antenna is used for the exchange of data and transmission energy required for the chip which is the key component of the system for data storage and transmission. As for passive RFID tags, a field created as described above is used to supply power to microchip circuits; as for active RFID tags, the energy is supplied from an integrated battery. A microchip then produces waves that transmit the tag back to the reader which converts them into a digital form $[2,4]$. The maximum distance for transponders depends on the tag sensitivity, mutual position, orientation and polarisation of the antenna and the tag, distance between the reader and the tag, the speed of tag motion within the read zone, utilisation of the carrier frequency, noise, several tags placed next to each other, obstacles, etc. [5].

The most frequent categorisation of RFID components and systems is based on the frequency band, type of identification element, and application of RFID. There are many types of RFID frequencies or RFID frequency bands that may be used in these systems. The most frequently used are 4 frequency bands, in particular: low frequency band, high frequency band, ultra-high frequency band, and microwave frequency [6].

Technical parameters of RFID tags specified by manufacturers are often incorrect or they do not include the parameter required for a particular application. It is difficult to predict how this component will be deported in the real-world environment of a particular application $[7,8]$.

The article [9] deals with experimental verification of qualitative properties of an RFID transponder, applying the regression analysis and by conducting experiments in laboratory conditions, in an expert laboratory. These experimental measurements were used to create regression models of the effects of external factors on the readability of the RFID transponder.

\section{Material and methods}

\subsection{Problem formulation}

The basic technological operations within the production of conveyor belts [10] include, in addition to the preparation of rubber compounds and confection, also vulcanisation. Hot laying of cover layers is carried out on a 4-roll combined line. When the cover layers are applied to the belt carcass (confection), it is important to inspect the thickness of the 
prepared cover layers, the width and thickness of the carcass, as well as the thickness of the uncoated conveyor belt. Vulcanisation is carried out in single-daylight and double-daylight vulcanising hydraulic presses where heated steam is used as the heating medium. Vulcanising plates are steam-heated up to the prescribed temperature. This facilitates precise regulation of the vulcanisation temperature.

The vulcanisation of conveyor belts may be accompanied by damage to RFID tags after which the data recorded in an RFID tag may become unreadable. Similarly, damage to RFID tags may occur when conveyor belts are used in the transport of hot materials, or due to ozone-induced ageing of conveyor belts exposed to intensive solar radiation. The objective of the article is to describe the experimental research on RFID tags and the analysis of their behaviour in accelerated thermal ageing.

\subsection{Procedure and methods of the experimental research}

The methodology of the experimental research on the quality of conveyor belts comprised the following key steps:

- Printing RFID tags using the Zebra ZD500 printer. The printer supports direct thermal and thermal-transfer printing and is compatible with cartridges from all key suppliers. The descriptions of the printed tags were prepared in the BarTender tool;

- Preparation of test specimens to be used in the experiments. The sample of the EP 1000/5, $6+3 \mathrm{H}$ belt with the dimensions of $300 \mathrm{~mm} \times 300 \mathrm{~mm}$ was used to cut out the test specimens in the ATOM hydraulic press (Fig. 1). The test specimen width was $54 \mathrm{~mm}$ and the length was $300 \mathrm{~mm}$. The test specimens were marked with Roman numerals I., II., and III.;

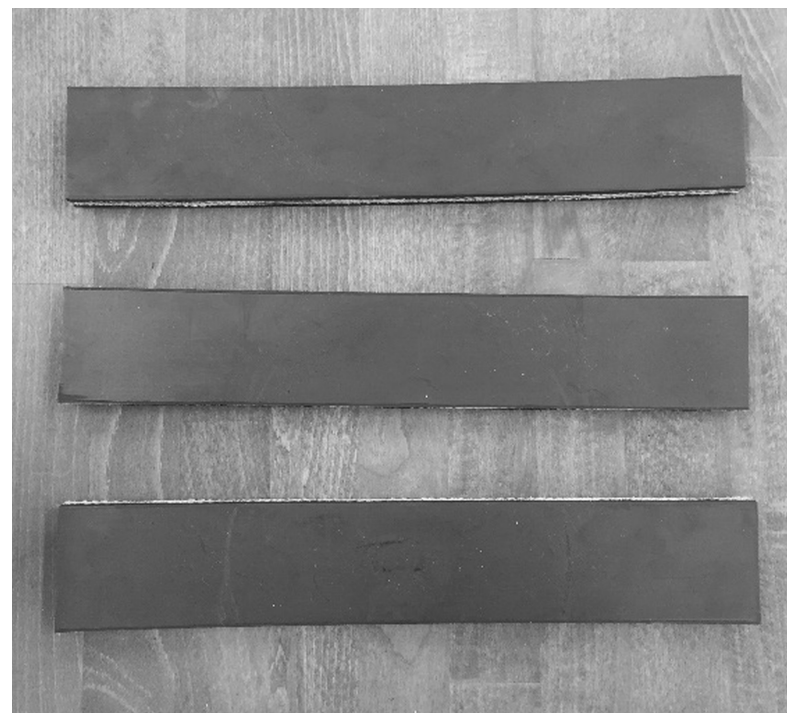

Fig. 1. Preparation of test specimens.

- Insertion/embedment of tags into test specimens (conveyor belts) is shown in Fig. 2.; 


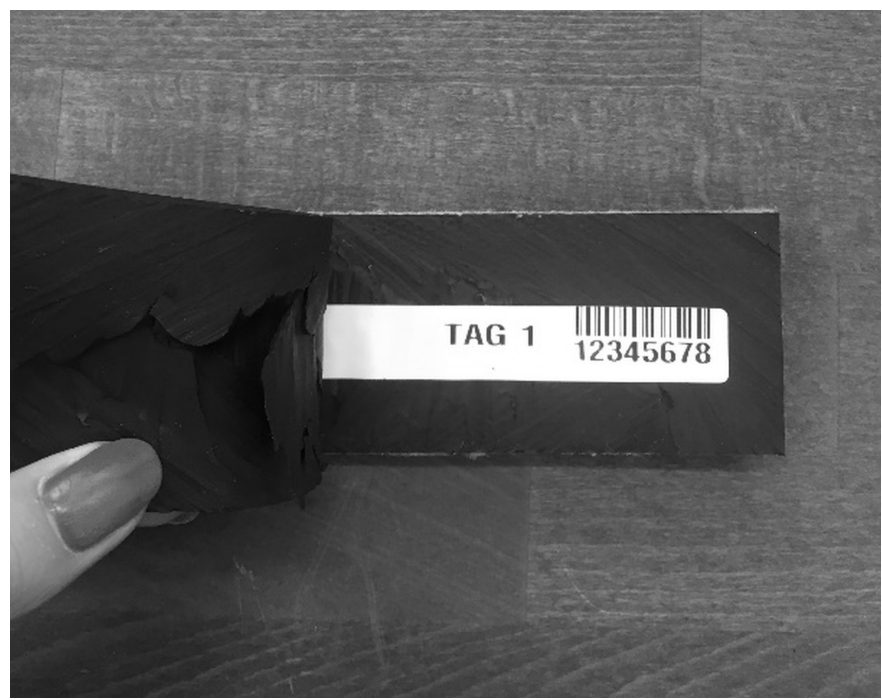

Fig. 2. Insertion of the tag into the test specimen.

- Vulcanisation of the test specimens;

- Accelerated thermal ageing of the test specimens. The prepared specimens were subsequently put into a drying oven with the temperature set to $250{ }^{\circ} \mathrm{C}$. The regulator was closed and the air flow was $60 \%$. An external sensor connected to the logger was placed into the drying oven. The logger was recording the measured temperatures inside the drying oven.

- Verification of readability of RFID tags after ageing.

\section{Results and discussion}

The purpose of the experimental research was to assess the quality of conveyor belts containing RFID tags after exposure to accelerated thermal ageing. The method of artificial ageing, pursuant to the DIN 53508 standard, was applied to investigate disintegration of rubber for which there is a risk of exposure to higher temperatures or higher oxygen pressures. The DIN 53508:

- determines the creep rate for drying ovens with forced air circulation;

- recommends testing temperatures and intervals;

- contains formulas for the calculation of standard deviations, coefficient of variation, and confidence interval.

Specimen Testing I., Testing II., and Testing III., at the temperature of $250{ }^{\circ} \mathrm{C}$, were scheduled for the period of 3 days. However, it was not possible to complete the experiment due to a safety hazard. The test lasted for 65 minutes; afterwards, the specimens were removed from the drying oven due to ignition of the tags inserted in the belt which was manifested by unusual smell and the presence of smoke. It was necessary to open the drying oven for inspection. It was observed that the tag specimens were burnt on their edges, but no flame was visible. They were then removed and the test was terminated. Fig. 3 indicates that the test of the conveyor belt containing RFID tags was terminated early. 


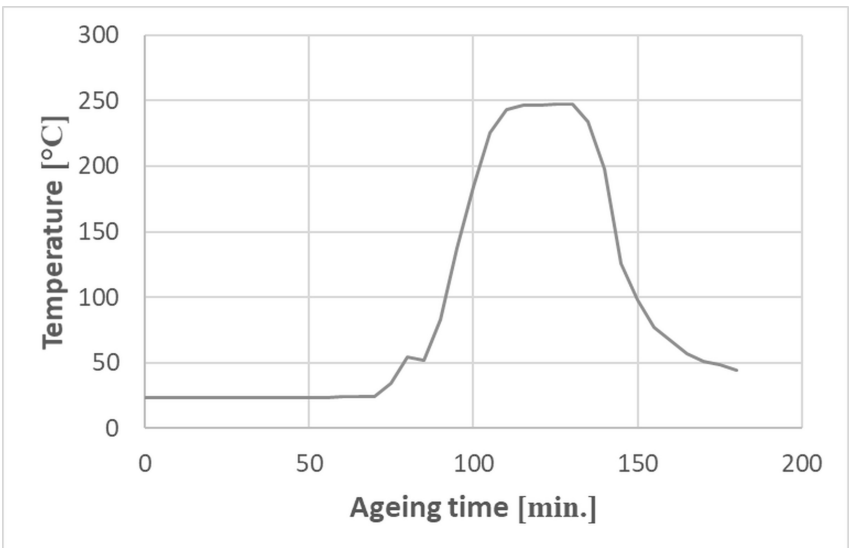

Fig. 3. Resulting plot of testing at $250^{\circ} \mathrm{C}$.

Considering the fact that the previously tested specimens were burnt, with this specimen the vulcanisation was applied and the testing temperature was reduced. The following plot (Fig. 4) represents the test of Specimen 4 in which the RFID tag was inserted between the top cover layer and the carcass.

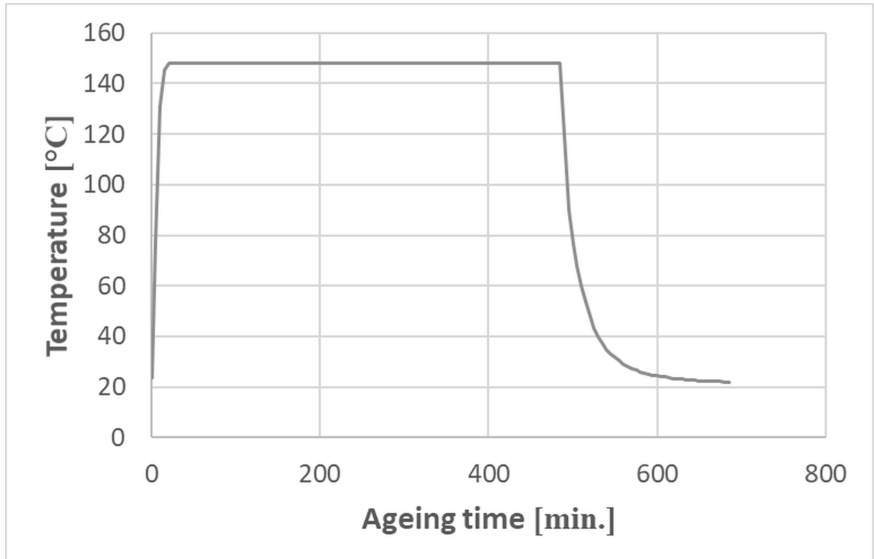

Fig. 4. Resulting plot of the test of RFID at the temperature of $150^{\circ} \mathrm{C}$.

The maximum temperature in the drying oven was $150{ }^{\circ} \mathrm{C}$. The temperature inside the drying oven was reported with the accuracy of $\pm 2{ }^{\circ} \mathrm{C}$; this means that the temperature ranged from $148{ }^{\circ} \mathrm{C}$ to $152{ }^{\circ} \mathrm{C}$. The logger accuracy was $0.2 \%$ of the measured value $\left(148.05^{\circ} \mathrm{C}\right)$ within the range of $100-260^{\circ} \mathrm{C}$.

Accuracy expressed in ${ }^{\circ} \mathrm{C}: 148.05 \times(0.2 / 100)=0.2961{ }^{\circ} \mathrm{C}$.

This means that the temperature range identified using the logger was 147.75-148.35 ${ }^{\circ} \mathrm{C}$, i.e., $148.05{ }^{\circ} \mathrm{C} \pm 0.3{ }^{\circ} \mathrm{C}$.

This experimental research was conducted using five RFID tags inserted into the EP $1000 / 56+3 \mathrm{H}$ conveyor belt. The belt was intended for hot, bulk and piece materials below $150{ }^{\circ} \mathrm{C}$. There were several alternatives for the insertion of RFID tags into the belt.

In the test specimen designated as I., the tag was inserted between the top cover layer and the carcass. As for the test specimen II., the tag was inserted between the second and third fabric plies of the belt carcass, and as for the test specimen III., the tag was inserted between the bottom cover layer and the carcass. The specimens were opened and the tags were exposed to direct ageing in the drying oven. For all these tags, the temperature was set 
to $250{ }^{\circ} \mathrm{C}$ and the ageing period was expected to last for three days. After the specimens were put into the drying oven, the temperature was set to $250{ }^{\circ} \mathrm{C}$; however, after 65 minutes of ageing there was smell and smoke in the room because of the ignition of the tags; this means that the ignition temperature, i.e., the lowest temperature at which a specimen ignites without the presence of an ignition source, was reached. Subsequently, the specimens were removed.

After such experience, the specimens were vulcanised (spliced) so that the tags inserted in the conveyor belt were not directly exposed to ageing. The vulcanisation was possible for two of the specimens. One was marked with number 4 - the tag was inserted between the top cover layer and the belt carcass, and the other one was marked with number 5 - the tag was inserted between the second and third fabric plies of the belt carcass. During the vulcanisation, the tag no. 5, inserted between the second and third fabric plies, got partially abraded. Only the specimen no. 4 was used in the ageing test. For this specimen, the ageing temperature was set to $150{ }^{\circ} \mathrm{C}$ for the period of 8 hours. After eight hours, the drying oven was opened and the next day the specimen was taken out.

After the completion of both experiments, the specimens containing the tags were subjected to the test of tag readability. Although the specimens I. to III. were burnt on the edges, the tags were readable. Even the tag inside the specimen no. 4, in the vulcanised belt, was readable. Tag readability was not affected by the fact that the belt had been partially abraded during vulcanisation.

\section{Conclusion}

In spite of all difficulties accompanied by the preparation and experimental research, such as burnt edges of tag specimens, tag abrasion, vulcanisation of conveyor belt specimens, and the necessity of procuring a reader for reading conveyor belt specimens, the experimental research was successfully completed and the hypothesis determined at the beginning of the research was proven. On the basis of the hypothesis: "Are heat resistant EPC Gen 2 RFID tags suitable for the application in conveyor belts?" we may state that heat resistant EPC Gen 2 RFID tags are suitable for the application in conveyor belts. Tag readability was not degraded by vulcanisation or accelerated thermal ageing of conveyor belts. Considering the experiments described in this article it may be concluded that RFID tags may be implemented into conveyor belts to scan the conveyor belt quality.

This article is the result of the Project VEGA 1/0577/17 and APVV-18-0248.

\section{References}

1. J.V. Velibor, J.M. Danko, Vojnotehnički Glasnik/Military Technical Courier, LX, 118 (2012)

2. H. Lehpamer, RFID design principles (Artech House, Norwood, 2012)

3. P. Kolarovszki et al., Transport and Telecommunication, 17, 144 (2016)

4. K. Finkenzeller, RFID handbuch (HANSER, Germany, 2006)

5. K.V.S. Rao, P.V. Nitkin, S.F. Lam, IEEE Transactions on Antennas and Propagation, 53, 3870 (2005)

6. A. Pandey, Analog Ic Tips, An EE World Online Resource (2017) URL: https://www.analogictips.com/rfid-tag-and-readerantennas/?fbclid=IwAR0BNtyeeSDY ZeS6qALw7s6hMXAkhL82C5816HE3Usv4sMgwP4p-DBZoWqg

7. R. Hricova, M. Balog, Int. J. Eng. Res. Afr., 18, 130 (2015) 
8. M. Balog, M. Mindas, SMART CITY 360 Book Series, 166, 592 (2016)

9. M. Balog et al., Measurement, 94, 233 (2016)

10. D. Marasova et al., Measurement, 112, 47 (2017) 